\title{
Chronic gastrointestinal inflammation and cerebrovascular events
}

\author{
Martin Fishman MD FRCPC
}

\begin{abstract}
ARTICLES
Ghali WA, Quan H, Feasby TE. Helicobacter pylori and cerebrovascular disease. Stroke 2001;32:1936.

Keene DL, Matzinger MA, Jacob PJ, Humphreys P. Cerebral vascular events associated with ulcerative colitis in children. Pediatric Neurology 2001;24:238-43.
\end{abstract}

\section{ARTICLE SUMMARIES}

Ghali et al, from the University of Calgary, Alberta, reported a cross-Canada study of in-hospital stroke and death complicating carotid endarterectomy. Patients with a diagnosis of peptic ulcer disease (PUD) at the time of admission were found to have a higher likelihood of sustaining a stroke that those without PUD (10.3\% versus $4.1 \%, \mathrm{P}=0.022)$. Multivariate analysis adjusting for age, urgency of admission and medical comorbidity resulted in an odds ratio of 2.12 for stroke in patients with PUD.

Keene et al reported three pediatric cases in which a cerebral vascular complication resulted from active ulcerative colitis. The first patient was a five-year-old boy with extensive brain infarction due to intracranial venous stasis or thrombosis. The second patient was a 13-year-old girl with widespread ischemic cerebral injury immediately fol- lowing a subtotal colectomy. The third patient was a 12 year-old boy with sagittal sinus thrombosis. The case report literature is reviewed and current theories of thrombogenesis in inflammatory bowel disease (IBD) are summarized below.

\section{DISCUSSION}

Gastroenterologists are frequently involved in the management of patients with cerebrovascular disease (CVD), usually surrounding issues of feeding difficulties or gastrointestinal bleeding associated with salicylate or anticoagulant therapy. However, patients seldom incur a cerebrovascular event as a consequence of their gastrointestinal disease. Two recent Canadian-authored publications in the neurology literature remind us of the potential pathogenic role of chronic gastrointestinal inflammation in CVD. One pertains to chronic Helicobacter pylori infection, the other to IBD.

The article by Ghali et al revealed that patients with a history of PUD are twice as likely to have a stroke complicating carotid endarterectomy than those without. This has been an issue fraught with controversy. Most of the literature in this area addresses the role of $\mathrm{H}$ pylori as an atherogenic factor in coronary artery disease (CAD), although CVD has also been studied.

There are two proposed mechanisms by which $H$ pylori might promote ischemic events: as a direct vascular patho-

Richmond Health Science Centre, Richmond, British Columbia

Correspondence: Dr Martin Fishman, Richmond Health Science Centre, 250, 6091 Gilbert Road, Richmond, British Columbia V7C 5L9.

Telephone 604-273-4447, fax 604-273-4254, e-mail mfish@telus.net 
gen, or by upsetting the equilibrium between thrombosis and fibrinolysis by altering levels of inflammatory mediators. Regarding the former mechanism, $\mathrm{H}$ pylori has been identified in human carotid atherosclerotic plaques by some authors but not others $(1,2)$. However, more attention has been paid to the latter theory, particularly in relation to $\mathrm{CAD}$. Individuals with evidence of CAD have been shown to have a higher prevalence of $H$ pylori, even when correcting for other known risk factors. It has been proposed that this higher prevalence is due to elevated fibrinogen levels or peripheral white blood count (3). Similar data were found for atherosclerotic CVD (4). The more virulent CagA-positive $H$ pylori strains, which elicit a more vigorous systemic inflammatory response, have been found to be the specific strains associated with CAD (5). However, a more recent review of the literature, including two meta-analyses, has found little evidence to support the hypothesis that $H$ pylori plays a major role in atherogenesis (6).

In contrast, the literature on CVD complicating IBD is based largely on case reports. The paper by Keene et al is no exception. In further contrast, cerebrovascular events in patients with IBD are thought to arise from a hypercoagulable state, or rarely from vasculitis, as opposed to atherosclerosis. This is underlined by the relatively high incidence of IBD-related CVD in children compared with adults, and by the large proportion of venous as opposed to arterial events. Results of autopsy studies suggest that $8 \%$ of IBD patients have sustained a thromboembolic cerebrovascular injury (7). The majority of these events are thought to occur in relation to the degree of IBD activity (8).

The mechanisms underlying vascular thrombosis in IBD have been recently reviewed (9). Pathogenesis is still poorly understood but likely multifactorial. Factor $\mathrm{V}$ Leiden probably plays a significant role in predisposing patients with thrombophilic IBD thrombogenesis. Romagnuolo et al (10) in Edmonton, Alberta, also demonstrated an increased prevalence of hyperhomocysteinemia in patients with IBD - another recognized thrombotic risk factor.
To a gastroenterologist, the possible vascular complications of $\mathrm{H}$ pylori infection are at least curious, and at best provocative, but currently carry few if any clinical implications. On the other hand, the occurrence and management of thromboembolic disease in IBD patients pose significant challenges. I have been involved in managing two such patients during the past year; both developed deep vein thrombosis while actively bleeding from severe ulcerative colitis. One patient was successfully treated with systemic corticosteroid therapy and placement of an inferior vena cava filter, the other required urgent colectomy. Acute central neurological events in our IBD patients should also alert us to the possibility of a thrombotic vascular complication.

\section{REFERENCES}

1. Ameriso SF, Fridman EA, Leigurada RC, Sevlever GE. Detection of Helicobacter pylori in human carotid atherosclerotic plaques. Stroke 2001;32:385-91.

2. Malnick SDH, Goland S, Kaftoury A, et al. Evaluation of carotid arterial plaques after endarterectomy for Helicobacter pylori infection. Am J Cardiol 1999;83:1586-7.

3. Patel P, Mendall MA, Carrington D, et al. Association of Helicobacter pylori and Chlamydia pneumoniae infections with coronary heart disease and cardiovascular risk factors. Br Med J 1995;311:711-4.

4. Markus HS, Mendall MA. Helicobacter pylori infection: a risk factor for ischaemic cerebrovascular disease and carotid atheroma. J Neurol Neurosurg Psychiatry 1998;64:104-7.

5. Pasceri V, Cammarota G, Patti G, et al. Association of virulent Helicobacter pylori strains with ischemic heart disease. Circulation 1998;97:1675-9.

6. Kusters JG, Kuipers EJ. Helicobacter and atherosclerosis. Am Heart J 1999;38:S523-7.

7. Graef V, Baggenstoss AH, Sauer WG, et al. Venous thrombosis occurring in nonspecific ulcerative colitis. A necropsy study. Arch Intern Med 1966;117:377-82.

8. Retsky JE, Kraft SC. The extraintestinal manifestations of inflammatory bowel disease. In: Kirsner JB, Shorter RG, eds. Inflammatory Bowel Disease, 4th edn. Baltimore: Williams and Wilkinson, 1995.

9. Koutroubakis IE. Unraveling the mechanisms of thrombosis in inflammatory bowel disease. Am J Gastroenterol 2001;96:1325-7.

10. Romagnuolo J, Fedorak RN, Dias VC, et al. Hyperhomocysteinemia and inflammatory bowel disease: prevalence and predictors in a crosssectional study. Am J Gastroenterol 2001;96:2143-9. 


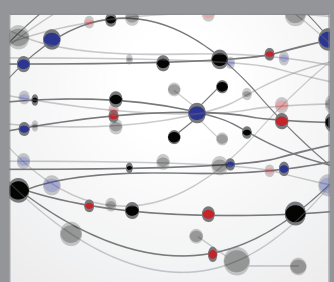

The Scientific World Journal
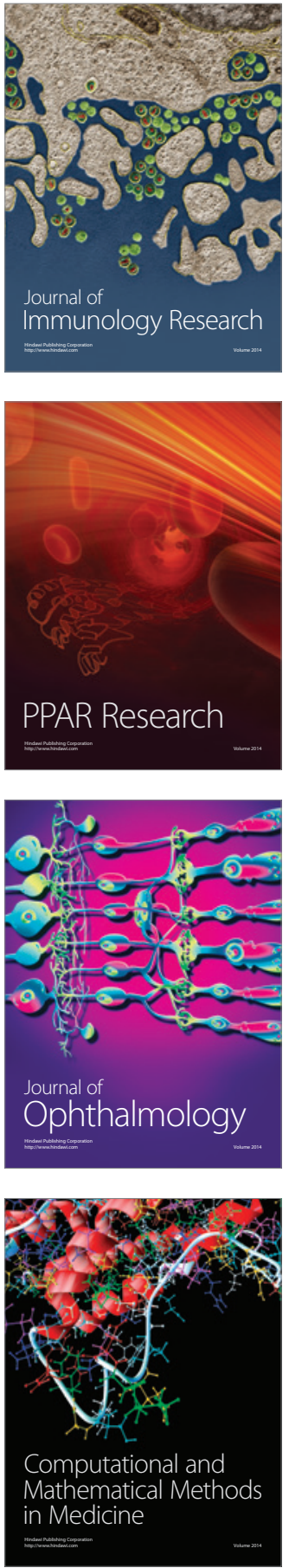

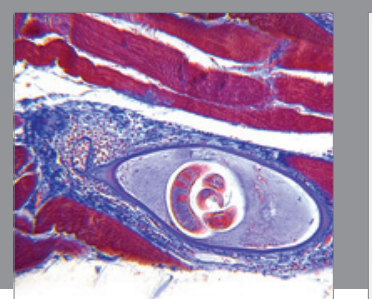

Gastroenterology Research and Practice

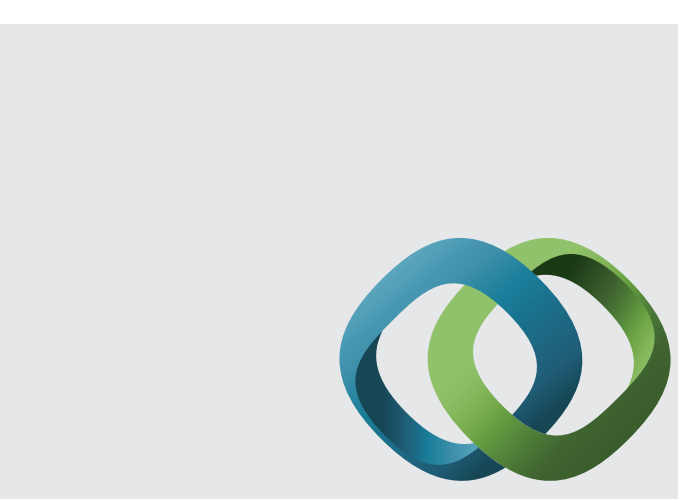

\section{Hindawi}

Submit your manuscripts at

http://www.hindawi.com
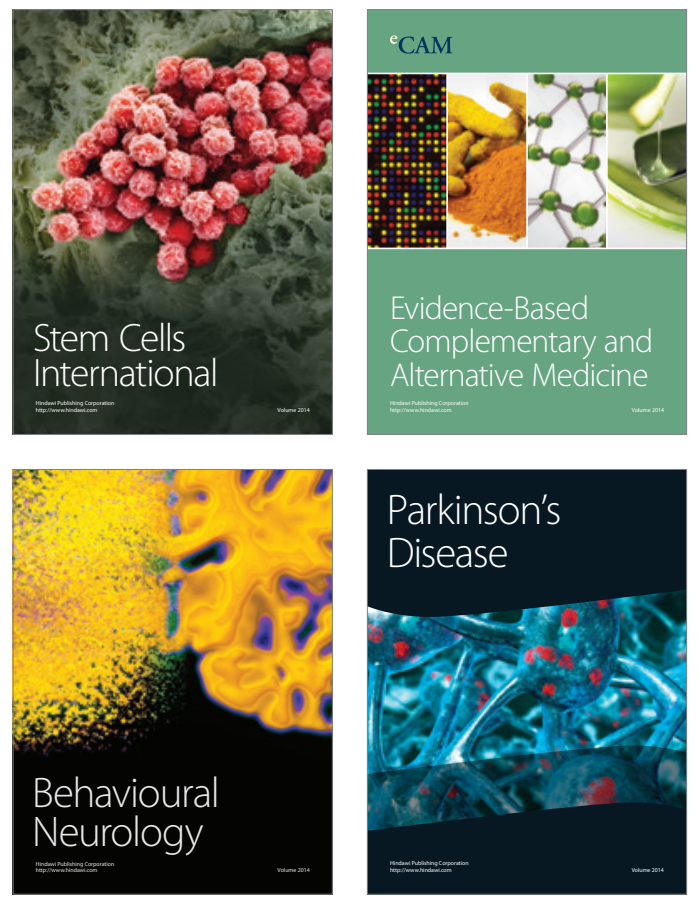
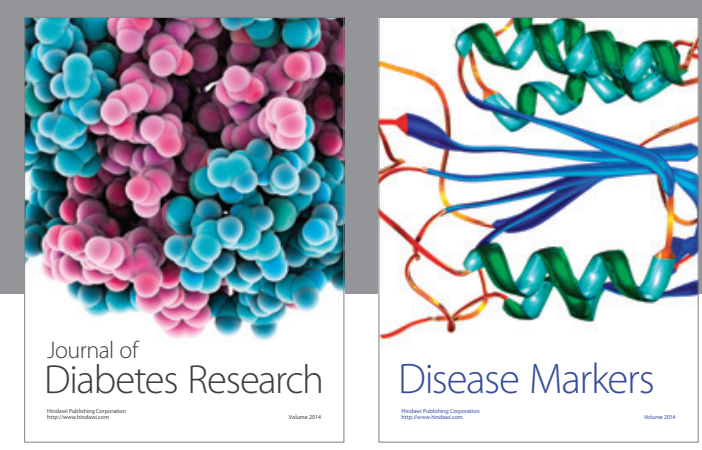

Disease Markers
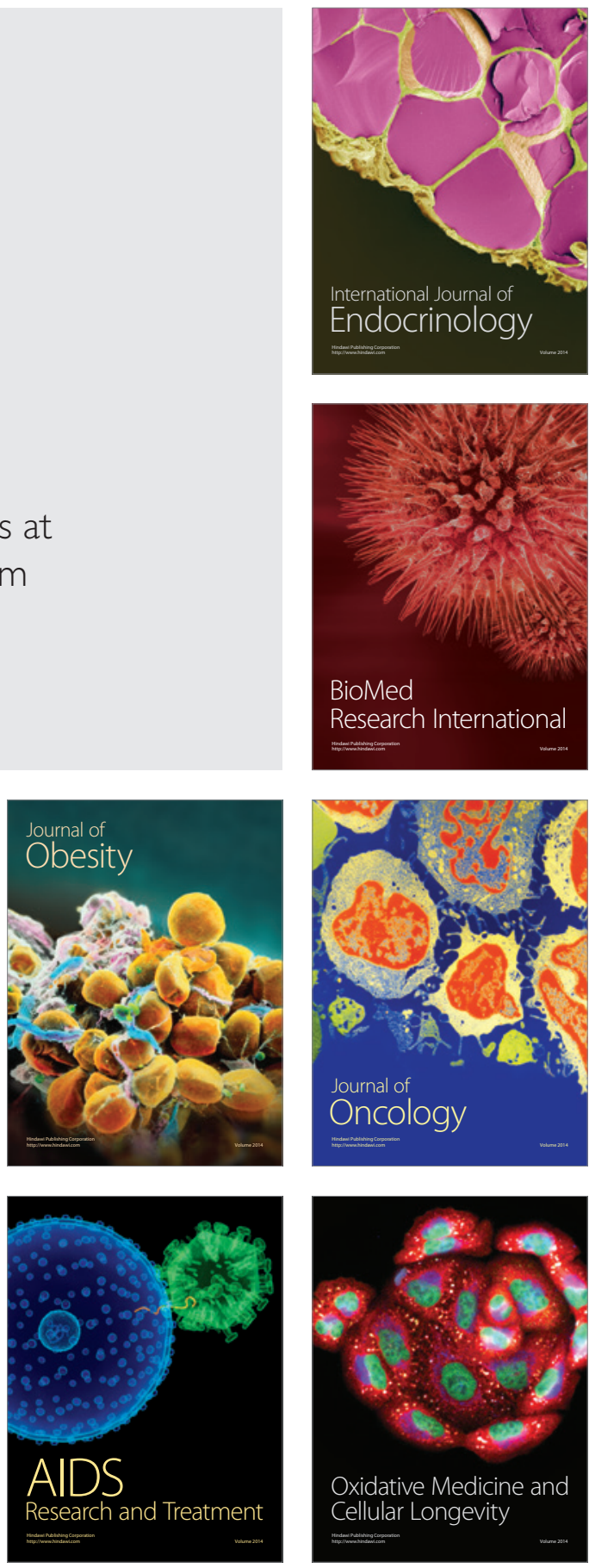